\title{
Robotic anatomical resection of liver segment 4 with glissonian approach and selective hepatic artery clamping
}

\author{
Marcel Autran C MACHADO, André O ARDENGH, Murillo M LOBO FILHO, \\ Bruno H MATTOS and Fábio F MAKDISSI
}

Received: 27 July 2020

Accepted: 17 September 2020

\begin{abstract}
Minimally invasive surgery has increased in the last decade, including liver procedures. The laparoscopic technique is considered safe and effective. However, this technique is still used in selected patients and in specialized centers with greater surgical volume ${ }^{(1,2)}$. Conventional laparoscopy has some limitations, including twodimensional view, unstable camera platform, and the use of rigid instruments with a limited degree of motion, which makes complex liver resection more difficult. Robotic system provides a good opportunity to perform even difficult procedures in the minimally invasive context but still restricted to few trained surgeons. The usefulness of the robotic platform in liver resection is still debated. However, patients who need complex liver procedures are good candidates for robotic approach. Procedures that require excellent accuracy and dexterity are the best candidates for robotic surgery ${ }^{(3-5)}$. This video shows a robotic resection of liver segment 4 using the glissonian approach and selected hepatic artery clamping in a patient with a single breast liver metastasis (FIGURES 1-2). We present the case
\end{abstract}

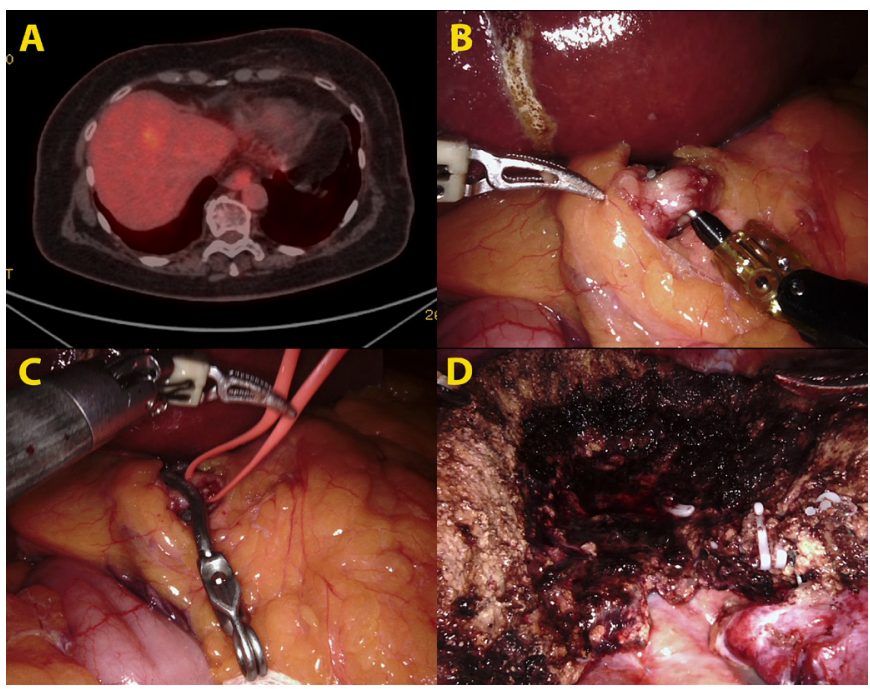

FIGURE 1. Robotic anatomic resection of liver segment 4.

A. PET-CT shows a single liver metastasis. B. Intraoperative view of dissection of common hepatic artery. C. Intraoperative view of selective hepatic artery clamping. D. Intraoperative view after completion of S4 resection. of a 79-year-old woman with previous history of a right mastectomy 10 years before and laparoscopic cholecystectomy. During follow up, an increase in tumor markers was observed that raised a suspicion of recurrence. PET-CT disclosed a 3-cm single liver metastasis in the segment 4 . Multidisciplinary team decided for resection of liver segment 4 (E-VIDEO*). Robotic approach was proposed, and consent was obtained. The patient was placed in a supine position and $30^{\circ}$ reverse Trendelenburg position. Robotic surgery was performed using the da Vinci Xi robotic platform (Intuitive Surgical Inc., Sunnyvale, CA). This technique used five trocars. A pneumoperitoneum was created using an open technique in the infra-umbilical port. The pneumoperitoneum was established at $14 \mathrm{mmHg}$. The remaining trocars were inserted under direct vision. During this technique, the surgeon is seated at the robotic console and the assistant surgeon stands on the patient's left side. The assistant surgeon performs,

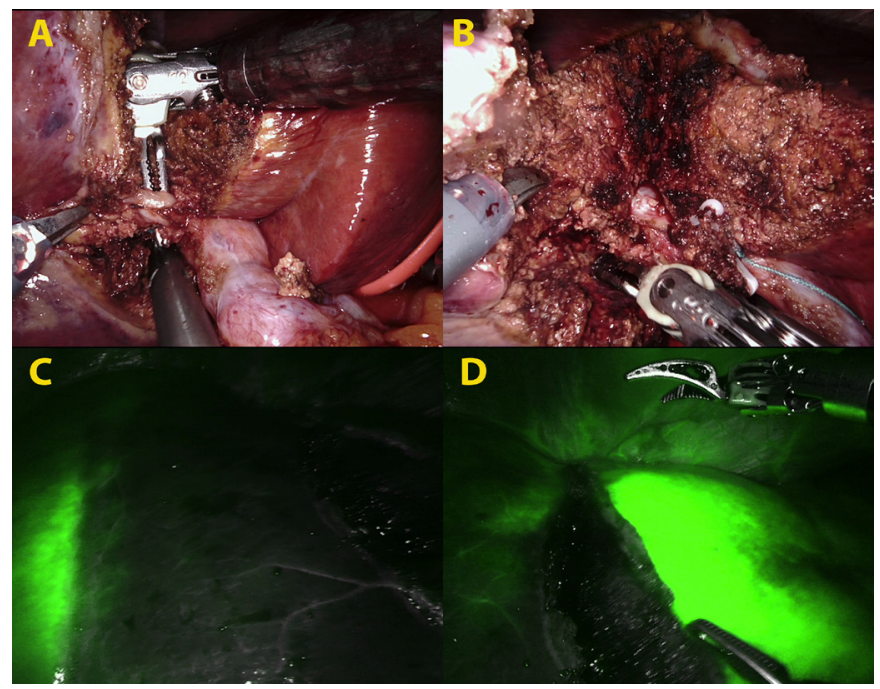

FIGURE 2. Robotic anatomic resection of liver segment 4 .

A. Intraoperative view: pedicle from segment $4 \mathrm{~B}$ is encircled. $\mathrm{B}$. Intraoperative view: pedicle from segment $4 \mathrm{~A}$ is encircled. C. Fluorescent image after injection of Indocyanine green shows $\mathrm{S} 4$ ischemic and perfused right liver. D. Fluorescent image after injection of Indocyanine green shows S4 ischemic and perfused segments 2 and 3 . 
suction, clipping, and changes the robotic instruments. After docking the robotic system, adhesions from previous surgery are divided and liver ultrasound is used to locate the tumor and to stablish the surgical margins. Common hepatic artery is dissected, and selectively clamped ${ }^{(6)}$. Liver parenchyma is divided right from the insertion of the round ligament and glissonian pedicles from segments 4B and $4 \mathrm{~A}$ are subsequently identified, ligated and divided, resulting in ischemic delineation of the entire segment 4. Indocyanine green fluorescent imaging was used to check ischemic area. The liver is then transected with robotic bipolar forceps under continuous saline irrigation and scissors. Ultrasound is constantly used to check surgical margins and relationship with major hepatic veins, specially the middle hepatic vein which is found within the posterior area of resection and ligated. Surgical specimen is removed inside a plastic retrieval bag through extension of the infra-umbilical incision and anatomical resection of liver segment 4 is completed. Operative time was 205 minutes, with minimal bleeding, and no need for blood transfusion. There was no need of intensive care unit and she was discharged on the 4th postoperative day. She is asymptomatic 15 months after the procedure. Robotic anatomical liver resection is feasible and safe. Glissonian approach allows for a precise anatomical resection ${ }^{(1)}$ and selective hepatic artery clamping is useful to reduce bleeding and liver ischemia. Long-term results, cost-benefit analysis as well learning curve studies are necessary ${ }^{(5,7)}$. This video shows main steps (E-VIDEO*) necessary to perform this complex operation.

\section{Authors' contribution}

Machado MA, Lobo Filho M and Makdissi FF carried out the operative procedure. Ardengh $\mathrm{AO}$ and Bruno H Mattos edited the video. Ardengh AO, Lobo Filho M and Makdissi FF supervised and commented on the manuscript. All authors discussed the results and contributed to the final manuscript.

\section{Orcid}

Marcel Autran C Machado: 0000-0002-4981-7607.

André O Ardengh: 0000-0001-6373-5598.

Murillo M Lobo Filho: 0000-0002-4716-0082.

Bruno H Mattos: 0000-0002-2849-5717.

Fábio Ferrari Makdissi: 0000-0001-8202-5890.

Machado MAC, Ardengh AO, Lobo Filho MM, Mattos BH, Makdissi FF. Ressecção anatômica do segmento 4 do fígado por via robótica com acesso glissoniano e oclusão seletiva da artéria hepática. Arq Gastroenterol. 2021;58(1):127-8.

\section{REFERENCES}

1. Machado MA, Surjan RC, Basseres T, Schadde E, Costa FP, Makdissi FF. The laparoscopic Glissonian approach is safe and efficient when compared with standard laparoscopic liver resection: Results of an observational study over 7 years. Surgery. 2016;160:643-51.

2. Wakabayashi G, Cherqui D, Geller DA, Buell JF, Kaneko H, Han HS, et al. Recommendations for laparoscopic liver resection: a report from the second international consensus conference held in Morioka. Ann Surg. 2015;261: 619-29.

3. Machado MAC, Surjan RC, Makdissi F. Robotic ALPPS. Ann Surg Oncol. 2020;27:1174-9.
4. Machado MA, Mattos BV, Lobo Filho MM, Makdissi F. Robotic Resection of Hilar Cholangiocarcinoma. Ann Surg Oncol. 2020;27:4166-70. doi:10.1245/ s10434-020-08514-6.

5. Tsung A, Geller DA, Sukato DC, Sabbaghian S, Tohme S, Steel J, et al. Robotic versus laparoscopic hepatectomy: a matched comparison. Ann Surg. 2014;259:549-55.

6. Nomi T, Fuks D, Agrawal A, Govindasamy M, Araki K, Gayet B. Modified Pringle maneuver for laparoscopic liver resection. Ann Surg Oncol. 2015;22:852.

7. Troisi RI, Pegoraro F, Giglio MC, Rompianesi G, Berardi G, Tomassini F, et al Robotic approach to the liver: Open surgery in a closed abdomen or laparoscopic surgery with technical constraints? Surg Oncol. 2020;33:239-48. 